\title{
Association between maternal gluten intake and type 1 diabetes in offspring: national prospective cohort study in Denmark
}

\author{
Julie C Antvorskov, ${ }^{1}$ Thorhallur I Halldorsson, ${ }^{2,3,4}$ Knud Josefsen, ${ }^{1}$ Jannet Svensson, ${ }^{5}$ \\ Charlotta Granström, ${ }^{2}$ Bart O Roep, ${ }^{6,7}$ Trine H Olesen, ${ }^{2}$ Laufey Hrolfsdottir, ${ }^{8}$ Karsten Buschard, ${ }^{1}$ \\ Sjudur F Olsen, ${ }^{2,9}$
}

For numbered affiliations see end of article.

Correspondence to: K Josefsen knud@eln.dk

(ORCID: 0000-0002-5093-2901)

Additional material is published online only. To view please visit the journal online.

Cite this as: BMJ 2018;362:k3547 http://dx.doi.org/10.1136/bmj.k3547

Accepted: 26 July 2018

\section{ABSTRACT}

OBJECTIVE

To examine the association between prenatal gluten exposure and offspring risk of type 1 diabetes in humans.

\section{DESIGN}

National prospective cohort study.

SETTING

National health information registries in Denmark. PARTICIPANTS

Pregnant Danish women enrolled into the Danish National Birth Cohort, between January 1996 and October 2002.

\section{MAIN OUTCOME MEASURES}

Maternal gluten intake, based on maternal consumption of gluten containing foods, was reported in a 360 item food frequency questionnaire at week 25 of pregnancy. Information on type 1 diabetes occurrence in the participants' children, from 1 January 1996 to 31 May 2016, were obtained through registry linkage to the Danish Registry of Childhood and Adolescent Diabetes.

\section{RESULTS}

The study comprised 101042 pregnancies in 91745 women, of whom 70188 filled out the food frequency questionnaire. After correcting for multiple pregnancies, pregnancies ending in abortions, stillbirths, lack of information regarding the pregnancy, and pregnancies with implausibly high or low energy intake, 67565 pregnancies ( 63529 women) were included. The average gluten intake was $13.0 \mathrm{~g} /$ day, ranging from less than $7 \mathrm{~g} /$ day to more than $20 \mathrm{~g} /$ day. The incidence of type 1 diabetes

\section{WHAT IS ALREADY KNOWN ON THIS TOPIC}

In an animal model of type 1 diabetes, a gluten free maternal diet during pregnancy almost completely prevented type 1 diabetes in offspring However, human studies have not shown an association between maternal gluten intake during pregnancy and the risk of type 1 diabetes in offspring

\section{WHAT THIS STUDY ADDS}

In a study population of 67565 pregnancies (63 529 women), the incidence of type 1 diabetes among children in the cohort was $0.37 \%(n=247)$ with a mean follow-up period of 15.6 years (standard deviation 1.4 )

The risk of type 1 diabetes in offspring increased proportionally with maternal gluten intake during pregnancy (adjusted hazard ratio 1.31 (95\% confidence interval 1.001 to 1.72 ) per $10 \mathrm{~g} /$ day increase of gluten intake)

Mothers with the highest gluten intake versus those with the lowest gluten intake ( $\geq 20 \mathrm{v}<7 \mathrm{~g} /$ day) had double the risk of type 1 diabetes development in their offspring (adjusted hazard ratio 2.00 (95\% confidence interval 1.02 to 4.00)) among children in the cohort was $0.37 \%(n=247)$ with a mean follow-up period of 15.6 years (standard deviation 1.4). Risk of type 1 diabetes in offspring increased proportionally with maternal gluten intake during pregnancy (adjusted hazard ratio 1.31 (95\% confidence interval 1.001 to 1.72 ) per $10 \mathrm{~g} /$ day increase of gluten). Women with the highest gluten intake versus those with the lowest gluten intake $(\geq 20$ $v<7 \mathrm{~g} /$ day) had double the risk of type 1 diabetes development in their offspring (adjusted hazard ratio 2.00 ( $95 \%$ confidence interval 1.02 to 4.00$)$ ).

\section{CONCLUSIONS}

High gluten intake by mothers during pregnancy could increase the risk of their children developing type 1 diabetes. However, confirmation of these findings are warranted, preferably in an intervention setting.

\section{Introduction}

The incidence of type 1 diabetes is highest in countries following a western lifestyle, ${ }^{1}$ and, until recently, ${ }^{2}$ it has been increasing at a rate of 3-4\% per year, especially in children below 5 years of age in Europe. ${ }^{3}$ This increase is faster than can be accounted for by genetic drift, pointing to the importance of environmental factors. Gluten proteins found in wheat, rye, and barley are believed to be important in diabetes development ${ }^{4}$; they are rich in proline and glutamine, ${ }^{5}$ which makes them highly hydrophobic and partly resistant to intestinal degradation. These properties make them more immunogenic than other dietary proteins, which are efficiently hydrolysed into single amino acids or dipeptides or tripeptides.

In an animal model of colitis, wheat gliadin and related peptic fragments were shown to activate mouse macrophages and human monocytes to produce proinflammatory cytokines. This action differed from any other food proteins. ${ }^{6}$ The amino acid sequence of wheat gliadin further facilitates the presentation on human leucocyte antigen (HLA)-DQ2 and HLA-DQ8. ${ }^{4}$

The effect of diet on the development of diabetes has been consistently shown in animal models of type 1 diabetes, the BioBreeding rat, ${ }^{7}$ and the non-obese diabetic (NOD) mouse. In NOD mice fed a lifelong gluten free diet, we found that incidence of diabetes fell from $64 \%$ to $15 \% .^{8}$ We then found that dietary gluten fed to healthy BALB/c mice changed the cytokine pattern in $\mathrm{T}$ cells towards an inflammatory cytokine profile and increased the proportion of T helper 17 cells (associated with development of autoimmunity, specifically in the pancreatic lymph nodes). ${ }^{9}{ }^{10} \mathrm{~A}$ gluten free diet also was shown to induce an antiinflammatory profile in NOD mice. ${ }^{9}$ The incidence 
of diabetes in the mice offspring was reduced even further from $64 \%$ to $8 \%$ if mothers were fed a gluten free diet only during pregnancy. ${ }^{11}$ This reduction was accompanied by an increase in islet number as well as decreased insulitis ${ }^{12}$ in the offspring.

Coeliac disease and type 1 diabetes share the same genetic background, with HLA being the predominant factor. ${ }^{13}$ Other common non-HLA loci also confer risk to both diseases. ${ }^{14}$ Coeliac disease is more prevalent among children diagnosed with having type 1 diabetes, ${ }^{15}$ and patients with diabetes plus unrecognised coeliac disease have an earlier onset of type 1 diabetes. If coeliac disease is diagnosed first, the risk of an individual developing type 1 diabetes decreases. ${ }^{16}$ In addition, the introduction of a gluten free diet in patients with a new diagnosis of type 1 diabetes diminishes the need for exogenous insulin, thereby prolonging the patients' period of remission. ${ }^{1718}$

Prenatal exposure to gluten could be relevant to type 1 diabetes development, because the process leading to islet autoimmunity may begin in fetal life. Seroconversion has a peak incidence or median at around 9-12 months of age, ${ }^{19-21}$ and thymic deletion of potentially self reactive $\mathrm{T}$ cells occurs mainly during the prenatal and neonatal periods, suggesting that these early stages could be a window for disease prevention. ${ }^{22}$ In two previous studies investigating maternal intake of gluten and the development of islet autoimmunity in HLA conferred individuals at risk, researchers found no association. ${ }^{23}{ }^{24}$ The aim of the present study was to investigate, in a large prospective birth cohort, whether maternal gluten intake is associated with the risk of type 1 diabetes in offspring.

\section{Methods}

\section{Population and study design}

The study was based on data from the Danish National Birth Cohort, ${ }^{25}$ in which pregnant Danish women were enrolled from January 1996 to October 2002. Eligible individuals were all pregnant women in Demark who were fluent in Danish. During the recruitment period, 91745 mothers were enrolled, but because women were allowed to enter the study more than once, the total number of pregnancies was 101042 . Women were recruited during their first antenatal visit to the general practitioner at 6-10 weeks of pregnancy. The study covered about 35\% of all births in Denmark during the recruitment period. Enrolled women participated in two telephone interviews at 12 and 30 weeks of gestation that collected extensive data on maternal lifestyle as well as past and present health characteristics. From these interviews, information on potential confounders were extracted. In addition, a food frequency questionnaire was sent to women at about 25 weeks of pregnancy. Familial follow-ups were conducted at six and 18 months postpartum, when information on breastfeeding was collected. Additional follow-ups were conducted when the children were 7,11 , and 14 years old. Selection bias for the present cohort was evaluated in a previous study, which found no difference in associations between maternal exposures (such as maternal smoking and prepregnancy weight) and preterm delivery and fetal growth, among those women recruited and those not recruited into the study. ${ }^{26}$

\section{Outcome measures}

Data about the development of type 1 diabetes in the children was obtained by unique linkage of person specific identifiers (from the Danish Civil Registration System (CPR)) to the Danish Registry of Childhood and Adolescent Diabetes (DanDiabKids), which covers children aged 0-18 years with a diagnosis of type 1 diabetes. For this study, the register covered diagnoses occurring from 1 January 1996 to 31 May 2016. The registry is validated annually. ${ }^{327}$ The time of clinical diagnosis of type 1 diabetes was set as the first day of insulin treatment in accordance with the EURODIAB criteria. ${ }^{28}$ The diagnosis in the DanDiabKids register was based on clinical presentation. Any doubt about the diagnosis was resolved by autoantibodies, C peptide, and genetic testing.

\section{Quantification of gluten intake}

Maternal diet was assessed at around week 25 of pregnancy by a validated food frequency questionnaire of 360 items that covered food intake during the previous four weeks. ${ }^{29}$ Food and nutrient intakes were then quantified on the basis of assumptions of standard portion sizes and by use of Danish food composition tables $^{3031}$ containing nutrient information of about 1030 foods available on the Danish market. If items in the questionnaire were not directly covered by records in the food composition tables, recipes were made with raw ingredients. For foods containing gluten, the amount of wheat, rye, and barley could be directly calculated for items that were based on recipes (bread, crispbread, pasta, lasagne, fast foods, cakes, and desserts); these amounts were estimated by expert judgments for other items such as beer, meatballs, and dumplings. The amount of gluten was then calculated on the basis of the protein content of wheat, rye, and barley with the conversion factors of $0.80,0.65$, and 0.50, respectively. ${ }^{32-35}$ As a quality check, we compared our estimated amount of gluten for individual food items to comparable work conducted in the Nurses' Health Study. ${ }^{36}$ Quantified gluten intake based on the Harvard data ${ }^{36}$ strongly correlated with our own intake estimates (Spearman's $r \sim 0.95$ ).

\section{Cohort attrition}

Of 101042 pregnant women recruited from 1996 to 2002, 70188 filled out and returned the food frequency questionnaire. Multiple pregnancies $(\mathrm{n}=1559)$, pregnancies ending in abortions $(n=79)$, stillbirths $(n=214)$, or lack of information on these pregnancy outcomes (n=96) left 68240 women available for analysis. In our analysis, we also excluded 343 women with implausibly high $(<25000 \mathrm{~kJ} /$ day $)$ or low $(<2500$ $\mathrm{kJ} /$ day) energy intake. In addition, we decided a priori 
to exclude women who had been diagnosed with having type 1 diabetes before pregnancy $(n=332)$ to prevent potential genetic confounding. These exclusions left us with 67565 pregnancies, corresponding to $67 \%$ of the full cohort and $96 \%$ of those women who completed the food frequency questionnaire. The 67565 pregnancies represented 63529 individuals, because 3992 and 44 women entered the study two and three times, respectively. The authors had access to the necessary data.

\section{Statistical analysis}

By use of summary statistics and thorough visual inspection, all variables were checked for coding errors values that were clearly implausible. Maternal gluten intake was categorised by percentiles $(<10,10-20,20$ $50,50-80,80-90, \geq 90)$. We then examined maternal offspring characteristics across these categories of intake using the mean and standard deviation for continuous variables and percentages for dichotomous variables. With these same categories of exposure, the association between maternal gluten intake during pregnancy and offspring risk of type 1 diabetes was examined by Cox regression. We used offspring age from birth up to May 2016 as the underlying timescale censoring if death or emigration from Denmark occurred (1217 events). Because women could enter the study repeatedly through different pregnancies, we used a robust sandwich covariance matrix estimate to account for interdependent observations. To test for linear trend, we used the median intake for each of the six gluten categories, entering these values as continuous variables in our regression models.

In our analysis, associations were first examined by an unadjusted model and then by two adjusted models (referred to as models 1 and 2). Characteristics that might influence the risk of type 1 diabetes were identified a priori and included as potential confounders in our adjusted analysis. In model 1 , we adjusted for:

- Mother's age at childbirth $(<25,25-35, \geq 35$ years; $0.9 \%(n=58)$ missing)

- Body mass index before pregnancy $(<18.5,18.5-25$, 25-30, $\geq 30 ; 5.8 \%(n=3924)$ missing $)$

- Parity $(0,1,<2 ; 4.4 \%$ ( $n=2946)$ missing)

- Smoking during pregnancy (never, occasional, <15 cigarettes/day, daily smokers $\geq 15$ cigarettes/day; $0.7 \%$ ( $\mathrm{n}=481$ ) missing)

- Parental socioeconomic status (high/intermediate level proficiency, skilled worker, unskilled worker/ unemployed, or student; 4.6\% ( $=3103)$ missing)

- Breastfeeding duration $(0,1,2,3,4,5,<6$ months; $27.8 \%$ ( $\mathrm{n}=18760)$ missing)

- Caesarean section (yes/no; no missing data)

- Offspring sex (male/female; no missing data)

- Total energy intake (by quintiles; no missing data) was also included to account for potential confounding by total energy intake. ${ }^{37}$

Information on breastfeeding was extracted from the telephone interviews conducted at six and 18 months postpartum, which had much lower participation (72.4\%) than the two prenatal interviews where information on most covariates was extracted. In model 2, additional adjustments were made for pre-existing maternal type 2 diabetes (no missing) and suspected gestational diabetes mellitus cases (no missing).

In our sensitivity analysis, we examined the association between maternal gluten intake during pregnancy and offspring risk of type 1 diabetes, stratifying by maternal age ( $<30 v \geq 30$ years), offspring sex (boys $v$ girls), maternal body mass index before pregnancy ( $<25 v \geq 25$ ), parity (nulliparous $v$ parous), and pre-existing diabetes (no diabetes $v$ type 2 diabetes or gestational diabetes mellitus). Together with the stratified results for women with gestational diabetes mellitus or type 2 diabetes, the association between maternal gluten intake and offspring risk of type 1 diabetes was also reported from women with underlying type 1 diabetes, although these women were a priori excluded from our data. The influence of time (offspring age at type 1 diabetes diagnosis) was examined in groups, with the end of follow-up occurring at 10 years of age on one hand and with follow-up starting at 10 years on the other. Computer codes are available on request.

\section{Patient and public involvement}

The study was conducted on historical data, so we were unable to involve patients. We have invited patients to help us develop our dissemination strategy.

\section{Results}

Mean maternal gluten intake was $13.0 \mathrm{~g} /$ day (standard deviation 5.3) and a total of 247 (0.37\%) offspring with type 1 diabetes were identified over a mean follow-up period of 15.6 (standard deviation 1.4) years. Women in the highest versus lowest category of gluten intake ( $\geq 20 v<7 \mathrm{~g} /$ day, table 1 ) were more likely to be of normal weight (that is, with a body mass index of $18.5-25 ; 66.3 \% v 59.3 \%)$, to be non-smoking $(75.0 \% v$ $70.0 \%$ ), to have breastfed their offspring for more than one month (65.8\% $v 59.7 \%)$, and to be parous $(51.7 \%$ $v$ 41.9\%). In absolute terms, only minor differences were observed in familial socio-occupational status and other characteristics across categories of increased maternal gluten intake. Pre-existing diabetes (type 2 or gestational diabetes mellitus) was not related to gluten intake.

With respect to maternal diet (table 2), intake of both whole and refined grains increased, as expected, substantially with higher gluten intake. Women in the highest intake category were eating excessive amount of grains per day compared with among those in the lowest intake category (about $477 \mathrm{~g} \mathrm{v}$ about $112 \mathrm{~g}$ ). In addition, energy intake increased considerably with higher absolute gluten intake, with women in the lowest intake category ( $<7 \mathrm{~g} /$ day $)$ having a mean energy intake of $7.2 \mathrm{~mJ} /$ day compared with $13.6 \mathrm{~mJ} /$ day among women in the highest intake category ( $\geq 20$ g/day). However, in terms of nutrient density, the 
Table 1 | Characteristics of study participants $(n=67565)$ according to gluten intake. Data are mean (standard deviation) for continuous variables and number (\%) for categorical variables. Values presented in table are before imputation of missing values; the number (\%) of missing values are given in the first column

Gluten intake by percentile (g/day; median (range))

\begin{tabular}{|c|c|c|c|c|c|c|c|c|}
\hline & \multirow[b]{2}{*}{$\begin{array}{l}\text { All participants } \\
n=67565\end{array}$} & & & & & & & \multirow[b]{2}{*}{$P^{*}$} \\
\hline & & $\begin{array}{l}<10 \%(5(0-7) \\
n=6756)\end{array}$ & $\begin{array}{l}10-20 \%(8(7-9) \\
n=6756)\end{array}$ & $\begin{array}{l}20-50 \%(11(9- \\
13) ; n=20269)\end{array}$ & $\begin{array}{l}50-80 \%(14(13- \\
17) ; n=20270)\end{array}$ & $\begin{array}{l}50-80 \%(18(17- \\
20) ; n=6756)\end{array}$ & $\begin{array}{l}\geq 90 \%(22(20- \\
66) ; n=6756)\end{array}$ & \\
\hline \multicolumn{9}{|c|}{ Maternal characteristics } \\
\hline \multicolumn{9}{|l|}{ Maternal age (years) } \\
\hline$<25$ & $5985(8.9)$ & $932(13.8)$ & $657(9.7)$ & $1641(8.1)$ & $1551(7.7)$ & $531(7.9)$ & $673(10.0)$ & \multirow[t]{4}{*}{$<0.01$} \\
\hline $25-35$ & $26452(39.2)$ & $2775(41.1)$ & $2801(41.5)$ & $8081(39.9)$ & $7750(38.2)$ & $2524(37.4)$ & $2521(37.3)$ & \\
\hline$\geq 35$ & $35070(51.9)$ & $3046(45.1)$ & $3294(48.8)$ & $10528(51.9)$ & $10950(54.0)$ & $3967(54.7)$ & $3555(52.6)$ & \\
\hline Missing & $58(0.9)$ & $4(0.0)$ & $5(0.1)$ & $19(0.1)$ & $19(0.1)$ & $5(0.1)$ & $7(0.10)$ & \\
\hline \multicolumn{9}{|c|}{ Body mass index before pregnancy } \\
\hline$<18.5$ & $2913(4.3)$ & $266(3.9)$ & $249(3.7)$ & $757(3.7)$ & $924(4.6)$ & $325(4.8)$ & $392(5.8)$ & \multirow[t]{5}{*}{$<0.01$} \\
\hline $18.5-25$ & $43203(63.9)$ & $4009(59.3)$ & $4199(62.1)$ & $12810(63.2)$ & $13230(65.3)$ & $4476(66.2)$ & $4479(66.3)$ & \\
\hline $25-30$ & $12435(18.4)$ & $1427(21.1)$ & $1350(20.0)$ & $3883(19.2)$ & $3623(17.9)$ & $1082(16.1)$ & $1070(15.8)$ & \\
\hline$\geq 30$ & $5090(7.5)$ & $589(8.7)$ & $563(8.3)$ & $1644(8.1)$ & $1378(6.8)$ & $486(7.2)$ & $430(6.4)$ & \\
\hline Missing & $3924(5.8)$ & $465(6.9)$ & $396(5.9)$ & $1175(5.8)$ & $1115(5.5)$ & $388(5.7)$ & $385(5.7)$ & \\
\hline Gestational age (days) & $280.3(12.4)$ & $280.0(12.7)$ & $280.2(12.6)$ & $280.4(12.5)$ & $280.5(12.0)$ & $280.5(12.0)$ & $280.1(12.4)$ & 0.10 \\
\hline Preterm pregnancy & $2989(4.4)$ & $323(4.8)$ & $321(4.8)$ & $921(4.5)$ & $830(4.1)$ & $283(4.2)$ & $311(4.6)$ & 0.05 \\
\hline \multicolumn{9}{|l|}{ Parity } \\
\hline 0 & $31596(48.9)$ & $3575(52.9)$ & $3501(54.0)$ & $9546(47.1)$ & $10349(46.8)$ & $3588(44.9)$ & $2987(46.1)$ & \multirow[t]{3}{*}{$<0.01$} \\
\hline$\geq 1$ & $33023(48.9)$ & $2828(41.9)$ & $2978(44.1)$ & $9819(48.4)$ & $9086(44.8)$ & $2901(52.7)$ & $3491(51.7)$ & \\
\hline Missing & $2946(4.4)$ & $353(5.2)$ & $278(4.1)$ & $904(4.5)$ & $835(4.1)$ & $298(4.4)$ & $278(4.1)$ & \\
\hline \multicolumn{9}{|c|}{ Smoking during pregnancy } \\
\hline Non-smoker & $50747(75.1)$ & $4729(70.0)$ & $5017(74.3)$ & $15336(75.7)$ & $15475(76.3)$ & $5126(75.9)$ & $5064(75.0)$ & \multirow[t]{4}{*}{$<0.01$} \\
\hline Occasional smoker & $8253(12.2)$ & $926(13.7)$ & $871(12.9)$ & $2463(12.2)$ & $2392(11.8)$ & 795 (11.8) & $806(11.9)$ & \\
\hline Daily smoker & $8084(12.0)$ & $1043(15.4)$ & $818(12.1)$ & $2311(11.4)$ & $2284(11.3)$ & $792(11.7)$ & $836(12.5)$ & \\
\hline Missing & $481(0.7)$ & $58(0.9)$ & $51(0.8)$ & $159(0.8)$ & $119(0.6)$ & $44(0.7)$ & $50(0.7)$ & \\
\hline \multicolumn{9}{|c|}{ Parental socioeconomic position } \\
\hline High level proficiency & $35759(52.9)$ & $3141(46.5)$ & $3528(52.2)$ & $10822(53.4)$ & $11075(54.6)$ & $3665(54.2)$ & $3528(52.2)$ & \multirow[t]{5}{*}{$<0.01$} \\
\hline $\begin{array}{l}\text { Medium level } \\
\text { proficiency }\end{array}$ & $17547(26.0)$ & $1900(28.1)$ & $1844(27.3)$ & $5338(26.3)$ & $5083(25.1)$ & $1702(25.2)$ & $1680(24.9)$ & \\
\hline Low level proficiency & $7752(11.5)$ & $1003(14.9)$ & $774(11.5)$ & $2233(11.0)$ & $1043(5.2)$ & $738(17.0)$ & $431(6.4)$ & \\
\hline Students & $3404(5.0)$ & $347(5.1)$ & $320(4.7)$ & $926(4.6)$ & $2185(10.8)$ & $337(5.0)$ & $819(12.1)$ & \\
\hline Missing & $3103(4.6)$ & $365(5.4)$ & $291(4.3)$ & $950(4.7)$ & $884(4.4)$ & $315(4.7)$ & $298(4.4)$ & \\
\hline \multicolumn{9}{|c|}{ Months of breastfeeding } \\
\hline $0-1$ & $5362(7.9)$ & $670(9.9)$ & $606(9.0)$ & $1611(8.0)$ & $1534(7.6)$ & $478(7.1)$ & $463(6.9)$ & \multirow[t]{4}{*}{$<0.01$} \\
\hline $1-6$ & $29704(44.0)$ & $1573(23.3)$ & $2766(40.9)$ & $8775(43.3)$ & $9335(46.1)$ & $3203(47.4)$ & $3164(46.8)$ & \\
\hline$\geq 6$ & $13829(20.5)$ & $2461(36.4)$ & $1512(22.4)$ & $4207(20.8)$ & $3697(19.6)$ & $1282(19.0)$ & $1285(19.0)$ & \\
\hline Missing & $18760(27.8)$ & $2052(30.4)$ & $1873(27.7)$ & $5676(28.0)$ & $5431(26.8)$ & $3202(47.4)$ & $1844(27.3)$ & \\
\hline Caesarean section & $5362(15.1)$ & $1071(15.9)$ & $1115(16.5)$ & $3141(15.5)$ & $2899(14.3)$ & $988(14.6)$ & $1002(14.8)$ & $<0.01$ \\
\hline $\begin{array}{l}\text { Suspected gestational } \\
\text { diabetes mellitus }\end{array}$ & $625(0.9)$ & $51(0.8)$ & $53(0.8)$ & $198(1.0)$ & $210(1.0)$ & $56(0.8)$ & $57(0.8)$ & 0.15 \\
\hline $\begin{array}{l}\text { Type } 2 \text { diabetes diag- } \\
\text { nosed before pregnancy }\end{array}$ & $522(0.8)$ & $50(0.7)$ & $52(0.8)$ & $163(0.8)$ & $153(0.8)$ & $52(0.8)$ & $52(0.8)$ & 0.99 \\
\hline \multicolumn{9}{|l|}{ Offspring characteristics } \\
\hline Type 1 diabetes & $247(0.37)$ & $20(0.30)$ & $20(0.30)$ & $69(0.34)$ & $73(0.36)$ & $30(0.44)$ & $35(0.52)$ & 0.18 \\
\hline Age at diagnosis (years) & $9.5(3.9)$ & $10.4(3.3)$ & $7.5(3.9)$ & $8.9(4.0)$ & $10.1(3.8)$ & $9.8(4.0)$ & $9.3(4.1)$ & 0.43 \\
\hline Male & $34658(51.3)$ & $3470(51.4)$ & $3532(52.3)$ & $10432(51.5)$ & $10366(51.1)$ & $3477(51.5)$ & $3381(50.0)$ & 0.20 \\
\hline Birth weight (kg) & $3.59(0.57)$ & $3.54(0.58)$ & $3.59(0.57)$ & $3.59(0.57)$ & $3.60(0.57)$ & $3.61(0.57)$ & $3.58(0.58)$ & $<0.01$ \\
\hline
\end{tabular}

${ }^{*} \mathrm{P}$ values evaluated by $t$ test for linear trend for continuous variables and $\mathrm{x}^{2}$ test for categorical variables.

energy coming from protein, carbohydrate, and fat was relatively similar across categories of gluten intake.

Maternal gluten intake was significantly associated with increased risk of type 1 diabetes in offspring in both unadjusted and covariate adjusted analyses (table 3). Compared with offspring born to mothers with the lowest gluten intake ( $<7 \mathrm{~g} /$ day), offspring of those with the highest intake ( $\geq 20 \mathrm{~g} /$ day) had double the risk of being diagnosed with having type 1 diabetes during follow-up (hazard ratio 2.00 (95\% confidence interval 1.02 to 4.00)). Risk of type 1 diabetes in offspring was positively associated with maternal gluten exposure during pregnancy: the association was significant (Ptrend $=0.016$ ) and increased monotonically. Only minor differences were observed between the unadjusted and covariate adjusted analyses.

In the stratified analyses (table 4), the association between maternal gluten intake during pregnancy and offspring risk of type 1 diabetes was more pronounced among older (age $\geq 30$ years), parous, and overweight or obese (body mass index before pregnancy $\geq 25$ ) mothers, with a non-significant but positive increase in risk observed in the other groups. A non-significant trend was observed between maternal gluten intake and offspring risk of type 1 diabetes among the few $(n=1147$, seven cases of type 1 diabetes in offspring) women with pre-existing type 2 or gestational diabetes mellitus (hazard ratio 2.08 (95\% confidence interval 


\begin{tabular}{|c|c|c|c|c|c|c|c|}
\hline & \multirow{2}{*}{$\begin{array}{l}\text { All partici- } \\
\text { pants } \\
(n=67565)\end{array}$} & \multicolumn{6}{|c|}{ Gluten intake by percentile (g/day; median (range))* } \\
\hline & & $\begin{array}{l}<10 \%(5 \\
(0-7))\end{array}$ & $\begin{array}{l}10-20 \%(8 \\
(7-9))\end{array}$ & $\begin{array}{l}20-50 \%(11 \\
(9-13))\end{array}$ & $\begin{array}{l}50-80 \%(14 \\
(13-17))\end{array}$ & $\begin{array}{l}50-80 \%(18 \\
(17-20))\end{array}$ & $\begin{array}{l}\geq 90 \%(22 \\
(20-66))\end{array}$ \\
\hline Total energy intake (m//day) & $10.1(0.3)$ & $7.2(0.2)$ & $8.2(0.2)$ & $9.2(0.2)$ & $10.7(0.2)$ & $11.9(0.2)$ & $13.6(0.3)$ \\
\hline Protein (E\%) & $15.7(2.4)$ & $16.7(3.0)$ & $16.4(2.6)$ & $16.0(2.3)$ & $15.5(2.3)$ & $15.0(2.2)$ & $14.6(2.2)$ \\
\hline Carbohydrate (E\%) & $51.4(5.8)$ & $50.9(7.1)$ & $51.5(5.9)$ & $51.4(5.6)$ & $51.4(5.5)$ & $51.4(5.4)$ & $51.5(5.7)$ \\
\hline Sugar (E\%) & $8.2(4.7)$ & $10.2(6.3)$ & $8.8(5.2)$ & $8.4(4.7)$ & $7.8(4.3)$ & $7.4(4.0)$ & $7.1(3.8)$ \\
\hline Fibre (E\%) & $2.2(0.6)$ & $1.6(0.5)$ & $2.0(0.5)$ & $2.1(0.5)$ & $2.3(0.5)$ & $2.4(0.5)$ & $2.4(0.5)$ \\
\hline Fat (E\%) & $31.4(6.3)$ & $31.1(7.1)$ & $30.5(6.2)$ & $31.0(6.0)$ & $31.5(6.2)$ & $31.9(6.4)$ & $32.3(6.8)$ \\
\hline Monounsaturated fatty acids (E\%) & $9.9(2.2)$ & $10.0(2.5)$ & $9.7(2.1)$ & $9.8(2.1)$ & $9.9(2.2)$ & $10.0(2.2)$ & $10.0(2.4)$ \\
\hline Polyunsaturated fatty acids (E\%) & $4.6(0.9)$ & $4.2(1.1)$ & $4.4(0.9)$ & $4.6(0.9)$ & $4.7(0.8)$ & $4.9(0.9)$ & $4.9(0.9)$ \\
\hline Saturated fatty acids (E\%) & $12.8(3.5)$ & $13.1(3.7)$ & $12.6(3.4)$ & $12.7(3.3)$ & $12.8(3.4)$ & $12.9(3.5)$ & $13.1(3.7)$ \\
\hline Whole grain (g/day) & $156(108)$ & $41(29)$ & $126(70)$ & $146(40)$ & $226(106)$ & $246(101)$ & $326(155)$ \\
\hline Refined grain (g/day) & $67(69)$ & $46(26)$ & $49(31)$ & $63(35)$ & $78(76)$ & $102(91)$ & $138(109)$ \\
\hline Breakfast cereals (g/day) & $25(45)$ & $25(42)$ & $30(46)$ & $26(45)$ & $24(43)$ & $16(43)$ & $13(39)$ \\
\hline
\end{tabular}

0.92 to 4.69) per $10 \mathrm{~g} /$ day increase in gluten intake). Women with no underlying type 2 or gestational diabetes mellitus $(n=66418,240$ cases of type 1 diabetes in offspring) showed a close to significant positive trend with gluten intake (hazard ratio 1.27 (95\% confidence interval 0.96 to 1.68 ) per $10 \mathrm{~g} /$ day increase in maternal gluten intake). The association between maternal gluten intake and type 1 diabetes in offspring was more pronounced among male offspring. No substantial differences were observed when stratifying by offspring age at diagnosis of type 1 diabetes.

In stability analyses, we firstly examined the association between total energy intake in mothers and risk of type 1 diabetes in offspring, because absolute intake of gluten and total energy intake were strongly related (table 2). We saw no association with total energy intake and offspring risk of type 1 diabetes $\left(P_{\text {trend }}=0.44\right.$, data not shown $)$. When expressing gluten intake as energy adjusted residuals ${ }^{37}$ instead of absolute intake as presented in table 2, we also observed a significant positive association with risk of type 1 diabetes in offspring $\left(\mathrm{P}_{\text {trend }}=0.028\right.$, table S1). Secondly, because we used relatively extreme categories for the highest and lowest gluten intake in mothers $(<10 \%$ and $\geq 90 \%$ intake groups), the association with risk of type 1 diabetes in offspring using groups of $20 \%$ as an explanatory variable was also explored (that is, $<20 \%$,
$20-40 \%, 40-60 \%, 60-80 \%, \geq 80 \%$ intake groups; table S2). Again, a significant association was observed $\left(P_{\text {trend }}=0.035\right)$, although the effect estimates were more modest, after collapsing the extreme categories.

Finally, unadjusted associations were explored between women who had one or more covariates were missing ( $n=21305,75$ cases of type 1 diabetes in offspring) and those with complete covariate information ( $\mathrm{n}=46505,175$ cases of type 1 diabetes in offspring). When modelling exposure as linear per 10 $\mathrm{g} /$ day increase in gluten intake, without adjusting for covariates (in order to obtain comparable estimates), we found that the effect estimates for the missing $(\beta=1.22$ (95\% confidence interval 0.82 to 1.81$))$ and complete case groups $(\beta=1.30$ (1.01 to 1.69$))$ were similar with overlapping confidence intervals.

\section{Discussion}

\section{Principal findings}

In this prospective cohort study of pregnant women, we found that maternal gluten intake during pregnancy was strongly associated with the subsequent risk of their offspring developing type 1 diabetes, with risk increasing proportionally (hazard ratio 1.31 (95\% confidence interval 1.001 to 1.72 ) per $10 \mathrm{~g} /$ day increase of gluten intake). A twofold risk of offspring developing type 1 diabetes was found when comparing mothers

\begin{tabular}{|c|c|c|c|c|}
\hline \multirow{2}{*}{$\begin{array}{l}\text { Maternal gluten intake, by } \\
\text { percentile* }^{*}\end{array}$} & \multirow{2}{*}{$\begin{array}{l}\text { No (\%) of cases of type } 1 \\
\text { diabetes in offspring/total }\end{array}$} & \multicolumn{3}{|c|}{ Hazard ratio $(95 \% \mathrm{Cl})$ of type 1 diabetes diagnosis in offspring } \\
\hline & & Unadjusted model & Adjusted model 1 & Adjusted model 2 \\
\hline $\begin{array}{l}\text { Continuous intake, per } 10 \mathrm{~g} / \text { day } \\
\text { increse }\end{array}$ & - & 1.28 (1.03 to 1.58$)$ & $1.31(1.002$ to 1.72$)$ & $1.31(1.001$ to 1.72$)$ \\
\hline $10 \%$ & $20(0.30) / 6761$ & 1.00 (reference) & 1.00 (reference) & 1.00 (reference) \\
\hline $10-20 \%$ & $20(0.30) / 6769$ & $0.99(0.53$ to 1.84$)$ & 1.07 (0.57 to 1.99$)$ & 1.06 (0.57 to 1.99$)$ \\
\hline $20-50 \%$ & $69(0.34) / 20289$ & $1.13(0.9$ to 1.86$)$ & $1.32(0.75$ to 2.30$)$ & $1.31(0.75$ to 2.30$)$ \\
\hline $50-80 \%$ & $73(0.36) / 20268$ & $1.19(0.73$ to 1.96$)$ & $1.46(0.82$ to 2.61$)$ & $1.46(0.82$ to 2.60$)$ \\
\hline $80-90 \%$ & $30(0.44) / 6750$ & 1.47 (0.84 to 2.59) & $1.82(0.93$ to 3.53$)$ & 1.81 (0.93 to 3.53) \\
\hline$\geq 90 \%$ & $35(0.52) / 6728$ & 1.72 (0.99 to 2.97) & $2.03(1.02$ to 4.01$)$ & $2.00(1.02$ to 4.00$)$ \\
\hline$P_{\text {trend }}$ & - & 0.013 & 0.016 & 0.016 \\
\hline
\end{tabular}




\begin{tabular}{|c|c|c|c|}
\hline \multirow[b]{2}{*}{ Maternal characteristics } & \multirow{2}{*}{$\begin{array}{l}\text { No (\%) of cases of type } \\
1 \text { diabetes in offspring/ } \\
\text { total No }\end{array}$} & \multicolumn{2}{|c|}{$\begin{array}{l}\text { Hazard ratio }(95 \% \mathrm{Cl}) \text { of type } 1 \text { diabetes diagnosis in } \\
\text { offspring per } 10 \mathrm{~g} / \text { day increase of maternal gluten intake }\end{array}$} \\
\hline & & Unadjusted model & Adjusted model \\
\hline \multicolumn{4}{|l|}{ Maternal age } \\
\hline$<30$ years & $134(0.41) / 32461$ & 1.29 (0.97 to 1.72$)$ & $1.13(0.78$ to 1.63$)$ \\
\hline$\geq 30$ years & $113(0.32) / 35104$ & $1.28(0.93$ to 1.77$)$ & 1.57 (1.09 to 2.29$)$ \\
\hline \multicolumn{4}{|l|}{ Parity } \\
\hline Not parous & $120(0.37) / 32738$ & 1.32 (0.96 to 1.82$)$ & $1.15(0.75$ to 1.76$)$ \\
\hline Parous & $127(0.36) / 34827$ & $1.24(0.93$ to 1.65$)$ & 1.49 (1.06 to 2.09$)$ \\
\hline \multicolumn{4}{|l|}{ Body mass index before pregnancy } \\
\hline$<25$ & $164(0.34) / 45506$ & $1.34(1.02$ to 1.75$)$ & $1.17(0.82$ to 1.65$)$ \\
\hline$\geq 25$ & $83(0.44) / 19059$ & $1.20(0.85$ to 1.69$)$ & $1.68(1.08$ to 2.60$)$ \\
\hline \multicolumn{4}{|l|}{ Maternal diabetes } \\
\hline $\begin{array}{l}\text { No pre-existing diabetes or gestational } \\
\text { diabetes mellitus }\end{array}$ & $240(0.36) / 66418$ & $1.24(1.00$ to 1.55$)$ & 1.27 (0.96 to 1.68$)$ \\
\hline $\begin{array}{l}\text { Pre-existing type } 2 \text { diabetes or suspected } \\
\text { gestational diabetes mellitus }\end{array}$ & $7(0.61) / 1147$ & $2.32(1.18$ to 4.57$)$ & $2.08(0.92$ to 4.69$)$ \\
\hline Type 1 diabetes $^{\star}$ & $9(2.71) / 332$ & $0.90(0.31$ to 2.67$)$ & $0.63(0.16$ to 2.40$)$ \\
\hline \multicolumn{4}{|l|}{ Offspring sex } \\
\hline Male & $132(0.38) / 34658$ & 1.63 (1.27 to 2.10$)$ & $1.41(1.02$ to 1.96$)$ \\
\hline Female & $115(0.35) / 32907$ & 0.93 (0.65 to 1.32$)$ & $1.19(0.76$ to 1.85$)$ \\
\hline \multicolumn{4}{|l|}{ Offspring age at diagnosis } \\
\hline$\leq 10$ years & $130(0.44) / 67565$ & $1.25(0.93$ to 1.67$)$ & 1.27 (0.88 to 1.82$)$ \\
\hline$<10$ years & $117(0.18) / 66576$ & 1.31 (0.95 to 1.79$)$ & $1.36(0.91$ to 2.03$)$ \\
\hline
\end{tabular}

who had the highest versus lowest gluten intakes ( $\geq 20 v<7$ g/day; hazard ratio 2.00 (95\% confidence interval 1.02 to 4.00)). Our stratified analyses suggest that parous, older, or overweight/obese women might be more sensitive to gluten intake than those who are younger or of normal weight. However, these results are at best suggestive, owing to the loss of statistical power when stratifying by individual maternal characteristics, and more evidence is needed to confirm these suggestive trends. Likewise, the mechanism that might be responsible for this effect is not known, but could include increased inflammation ${ }^{38-41}$ or increased intestinal permeability. ${ }^{4243}$

Gluten intake and total calorie intake were correlated in our dataset, and high maternal body mass index or gestational diabetes is associated with both type 1 and 2 diabetes in children. ${ }^{44-46}$ As a result, it could be hypothesised that the association observed in our present study could have been caused by high body mass index rather than by gluten. The involvement of body mass index is probably not the case, because we noted that high gluten intake inversely correlated with maternal body mass index. Thus, if diabetes development was triggered by high maternal body mass index, we would not observe a dose dependent association of gluten intake in the mothers, but rather an inverse effect.

\section{Strengths and limitations of study}

A major strength of our study was the study design. The data were gathered from one of the largest prospective birth cohorts, increasing the power in the presented associations, and the prospective design eliminated recall bias because food frequency questionnaires were collected before knowledge of the disease outcome. The use of a food frequency questionnaire is considered to be a reproducible and valid method to assess diet during pregnancy, ${ }^{478}$ and the register used to identify children with type 1 diabetes (DanDiabKids) is annually validated. ${ }^{27}$ Furthermore, comprehensive registry and interview data collected during and after pregnancy made it possible to adjust for a large number of confounders and perform sensitivity analyses, and our results were robust to adjustment for well established predictors of type 1 diabetes in offspring. Our use in Denmark of unique ID numbers (from the Danish Civil Registration System (CPR)) for every citizen enabled a follow-up of our cohort that was near $100 \%$ for identifying incident cases of type 1 diabetes in the children through linkage to the DanDiabKids register, which has full national coverage.

Despite the large study size, the statistical power of our study was still modest because of the low number of cases of type 1 diabetes $(n=247)$ in our study population, which was reflected by some associations that were only just below the threshold set for formal significance $(\alpha=0.05)$. In addition, the role of unmeasured or unidentified confounders can never be fully excluded in observational studies. Confirmation of our findings in another comparable but independent dataset is therefore warranted. Dietary assessment methods that rely on the participants' ability to report their habitual diet are inevitably subject to uncertainties, owing to the inherent difficulty in recalling diet accurately. However, food frequency questionnaires have proved useful for ranking individuals according to quantified dietary intake of foods and food constituents in large scale epidemiological studies, where the use of precise methods such as dietary records are not feasible. ${ }^{49}$ 
Although gluten containing foods are easy to identify, and the protein fractions of gluten in wheat, rye, and barley are known, gluten is also intentionally added during production to certain types of flour, bread, and other foods, which we were unable to account for. This unaccountable addition of gluten would lead to a systematic underestimation of intake. Also relevant to our intake estimation was that statistical associations including essential nutrients are commonly examined by transforming crude intake to nutrient densities or energy adjusted residuals. ${ }^{37}$ The underlying assumption is that the energy intake is roughly proportional to the physiological needs of each individual, meaning that it is the energy density of the nutrient under consideration that in most cases is the determinant of health. However, this assumption does not hold for non-essential nutrients or other substances that might be detrimental in absolute terms. Gluten is not an essential nutrient, and studies on gluten and type 1 diabetes in laboratory animals suggest that it is the absolute amount of gluten that influences the risk of type 1 diabetes. ${ }^{4}$ As a result, we based our analyses on the absolute gluten intake. Justifying this approach, and despite a strong correlation between absolute gluten and total energy intake (table 2), we found no indication in our sensitivity analyses to suggest that maternal energy intake was related to offspring type 1 diabetes risk. The same conclusions were reached when we used a more traditional way of accounting for energy intake, using energy adjusted residuals ${ }^{37}$ (table S1).

Another limitation was that we do not know whether mothers with a low intake of gluten during pregnancy also serve a low gluten diet to their infants. This factor could be important for type 1 diabetes development because the amount, timing, ${ }^{50-52}$ and mode of gluten introduction all seem to affect disease development. ${ }^{4}$ However, in our animal experiments, a gluten free diet fed to mothers during pregnancy was far more effective in preventing diabetes in the offspring than a gluten free diet fed to the offspring, ${ }^{11}$ suggesting that the intrauterine environment could be the decisive factor for the development of type 1 diabetes.

\section{Comparison with other studies}

To our knowledge, only two other studies have looked at the association of gluten intake in pregnancy and risk of type 1 diabetes in children. In both studies, researchers investigated at-risk children (HLA conferred susceptibility) and the development of $\beta$ cell autoantibodies. Lamb and colleagues ${ }^{23}$ investigated a cohort of 642 children whose mothers filled out a food frequency questionnaire covering the third trimester. Of these children, 27 developed autoimmunity. Virtanen and colleagues ${ }^{24}$ studied a cohort of 3723 infants, of whom 138 developed autoimmunity and whose mothers filled out a food frequency questionnaire postnatally, covering the eighth month of pregnancy. These two studies did not find an association between maternal gluten intake and development of autoantibodies in the children. Their findings differ from to our study results, and could be explained by multiple differences in the design of the two studies: inclusion of high risk study populations, use of a postnatally completed food frequency questionnaire, different outcomes and exposure times, insufficient statistical power, shorter follow-up time, or a setup that allowed for adjustment for fewer confounders. Thus, statistically well powered studies with information on potential confounders and evaluating childhood diabetes have currently been lacking to firmly establish whether prenatal gluten exposure is a risk factor for childhood diabetes.

\section{Conclusions and policy implications}

The possible effect of maternal gluten intake on risk of type 1 diabetes in offspring might be related to the complex interplay between diet, immune development, microbiota, and intestinal permeability, which could all affect the pathogenesis of type 1 diabetes. There are regional differences in the effect of probiotics and type 1 diabetes development as well as in the microbiome and structure of gluten and in the gluten content of crops. The effect of gluten intake during pregnancy could therefore vary geographically. In humans, the establishment of the microflora early in life might affect children's risk of chronic immune disorders; babies delivered by caesarean section have a $23 \%$ increased risk of onset of type 1 diabetes in childhood..$^{53}$

It was previously assumed that fetuses were sterile, but evidence suggests that the establishment of the fetus microflora could already start in utero, transferred from maternal intestinal microbiota. ${ }^{54}$ The colonisation of the child's intestine continues to develop after vaginal birth through contact with vaginal bacteria and maternal faeces, and is subsequently affected by breastfeeding and early infant feeding. Maternal intestinal and vaginal microbiota and the composition of breast milk are influenced by maternal diet (eg, gluten intake). ${ }^{55}$ Thus, high gluten intake, as reported during pregnancy, could reflect habitual diets that shape the maternal, and thus the neonatal, microbiome.

Our study suggests that high gluten intake in pregnancy might be a risk factor for type 1 diabetes in offspring. The association is moderate, suggesting a 50\% reduction in type 1 diabetes incidence among the children of mothers with the highest versus lowest gluten intake. This magnitude is comparable to results from other studies looking at other potential protective factors (that is, breastfeeding and D3 vitamin supplementation) in early childhood. ${ }^{56} 57$ However, more evidence is needed before changes to dietary recommendations could be justified. Confirmation is warranted, preferably in an intervention setting, or in other cohort studies. In this context, the safety of substituting gluten containing foods for other foods and nutrients should be investigated as well as the possibility of obtaining a larger effect by adherence to a completely gluten free diet. Whether a diet with a low gluten content during pregnancy changes the incidence of coeliac disease in children should be investigated, although a recent study did not support this concern. ${ }^{58}$ 


\section{AUTHOR AFFILIATIONS}

${ }^{1}$ Bartholin Institute, Rigshospitalet, Ole Måløes Vej 5, 2200 Copenhagen K, Denmark

${ }^{2}$ Centre for Foetal Programming, Department of Epidemiology Research, Statens Serum Institute, Copenhagen, Denmark

${ }^{3}$ Unit for Nutrition Research, Landspitali University Hospital, Reykjavik, Iceland

${ }^{4}$ Faculty of Food Science and Nutrition, University of Iceland, Reykjavik, Iceland

${ }^{5}$ Copenhagen Diabetes Research Center (CPH-DIRECT), Department of Children and Adolescents, Copenhagen University Hospital Herlev, Herlev, Denmark

${ }^{6}$ Department of Diabetes Immunology, Diabetes and Metabolism Research Institute at the Beckman Diabetes Research Institute, City of Hope, Duarte, CA, USA

${ }^{7}$ Departments of Immunohematology and Blood Transfusion, Leiden University Medical Centre, Leiden, Netherlands

${ }^{8}$ Department of Education, Science, and Quality, Akureyri Hospital, Akureyri, Iceland

${ }^{9}$ Department of Nutrition, Harvard T.H. Chan School of Public Health, Boston, MA, USA

Laura Sampson at the Department of Nutrition, Harvard TH Chan School of Public Health, provided data on gluten content in US cereals and foods.

Contributors: ICA initiated the study. SFO was responsible for the data collection. TIH, CG, THO, LH, and SFO were responsible for the dietary database within the Danish National Birth Cohort, including quantification of gluten intake, and JS for type 1 diabetes case validation. TIH and LH carried out the statistical analyses. JCA and $\mathrm{TIH}$ drafted the work. ICA, TIH, and KI wrote the final version of the manuscript. All authors participated in the interpretation of the results as well as revision of the manuscript. The corresponding author attests that all listed authors meet authorship criteria and that no others meeting the criteria have been omitted. TIH, CG, THO, and SFO had full access to the server where data were kept. Access by other authors was granted under supervision of those with who had direct access to data. JCA is the guarantor.

Funding: This study was supported by Kirsten and Freddy Johansens Foundation, and by the March of Dimes Foundation (6-FY-96-0240, 6-FY97-0553, 6-FY97-0521, 6-FY00-407), Innovation Fund Denmark (grant No 09-067124, Centre for Fetal Programming), Danish Heart Association, Sygekassernes Helsefond, and the Danish National Research Foundation. The funders had no influence on the study. Competing interests: All authors have completed the ICMJE uniform disclosure form at www.icmje.org/coi_disclosure.pdf and declare: support from the Kirsten and Freddy Johansens Foundation, March of Dimes Foundation, Innovation Fund Denmark, Danish Heart Association, Sygekassernes Helsefond, and the Danish National Research Foundation for the submitted work; no financial relationships with any organisations that might have an interest in the submitted work in the previous three years; no other relationships or activities that could appear to have influenced the submitted work.

Ethical approval: Data collection in the Danish National Birth Cohort was approved by the Danish National Ethics Board, and all participants provided written informed consent.

Data sharing: Computer codes for the statistical analyses are available on request. The data underlying the presented results in this paper can be shared by sending a request via the regular mechanism for obtaining access to data from the Danish National Birth Cohort (https://www.ssi.dk/English/RandD/Research\%20areas/ Epidemiology/DNBC/For\%20researchers/How\%20to\%20apply\%20 for\%20data.aspx).

The lead author affirms that the manuscript is an honest, accurate, and transparent account of the study being reported; that no important aspects of the study have been omitted; and that any discrepancies from the study as planned (and, if relevant, registered) have been explained.

This is an Open Access article distributed in accordance with the Creative Commons Attribution Non Commercial (CC BY-NC 4.0) license, which permits others to distribute, remix, adapt, build upon this work non-commercially, and license their derivative works on different terms, provided the original work is properly cited and the use is noncommercial. See: http://creativecommons.org/licenses/by-nc/4.0/.
1 Karvonen M, Tuomilehto J, Libman I, LaPorte R, World Health Organization DIAMOND Project Group. A review of the recent epidemiological data on the worldwide incidence of type 1 (insulindependent) diabetes mellitus. Diabetologia 1993;36:883-92. doi:10.1007/BF02374468

2 Harjutsalo V, Sund R, Knip M, Groop PH. Incidence of type 1 diabetes in Finland. JAMA 2013;310:427-8. doi:10.1001/ jama.2013.8399

3 Svensson J, Lyngaae-Jørgensen A, Carstensen B, Simonsen LB, Mortensen HB, Danish Childhood Diabetes Registry. Long-term trends in the incidence of type 1 diabetes in Denmark: the seasonal variation changes over time. Pediatr Diabetes 2009;10:248-54 doi:10.1111/j.1399-5448.2008.00483.x

4 Antvorskov JC, Josefsen K, Engkilde K, Funda DP, Buschard K. Dietary gluten and the development of type 1 diabetes. Diabetologia 2014;57:1770-80. doi:10.1007/s00125-014-3265-1

5 Shewry PR, Halford NG, Belton PS, Tatham AS. The structure and properties of gluten: an elastic protein from wheat grain. Philos Trans R Soc Lond B Biol Sci 2002;357:133-42. doi:10.1098/ rstb.2001.1024

6 Tlaskalová-Hogenová H, Tucková L, Stepánková R, et al. Involvement of innate immunity in the development of inflammatory and autoimmune diseases. Ann N Y Acad Sci 2005;1051:787-98. doi:10.1196/annals.1361.122

7 Scott FW. Food-induced type 1 diabetes in the BB rat. Diabetes Metab Rev 1996;12:341-59. doi:10.1002/(SICI)1099 0895(199612)12:4<341::AID-DMR173<3.0.CO;2-0

8 Funda DP, Kaas A, Bock T, Tlaskalová-Hogenová H, Buschard K. Gluten-free diet prevents diabetes in NOD mice. Diabetes Metab Res Rev 1999;15:323-7. doi:10.1002/(SICI)15207560(199909/10)15:5<323::AID-DMRR53<3.0.CO;2-P

9 Antvorskov JC, Fundova P, Buschard K, Funda DP. Dietary gluten alters the balance of pro-inflammatory and anti-inflammatory cytokines in T cells of BALB/c mice. Immunology 2013;138:23-33. doi:10.1111/imm.12007

10 Antvorskov JC, Fundova P, Buschard K, Funda DP. Impact of dietary gluten on regulatory T cells and Th17 cells in BALB/c mice. PLoS One 2012;7:e33315. doi:10.1371/journal.pone.0033315

11 Antvorskov JC, Josefsen K, Haupt-Jorgensen M, Fundova P, Funda DP, Buschard K. Gluten-free diet only during pregnancy efficiently prevents diabetes in NOD mouse offspring. J Diabetes Res 2016;2016:3047574. doi:10.1155/2016/3047574

12 Haupt-Jorgensen M, Larsen J, Josefsen K, et al. Gluten-free diet exclusively during pregnancy alleviates the signs of diabetes and celiac disease in NOD mouse offspring. Diabetes Metab Res Rev 2018. doi:10.1002/dmrr.2987.

13 Smigoc Schweiger D, Mendez A, Kunilo Jamnik S, et al. High-risk genotypes HLA-DR3-DQ2/DR3-DQ2 and DR3-DQ2/ DR4-DQ8 in co-occurrence of type 1 diabetes and celiac disease. Autoimmunity 2016;49:240-7. doi:10.3109/08916934.2016.1164144

14 Smyth DJ, Plagnol V, Walker NM, et al. Shared and distinct genetic variants in type 1 diabetes and celiac disease. $N$ Engl J Med 2008;359:2767-77. doi:10.1056/NEJMoa0807917

15 Hansen D, Bennedbaek FN, Hansen LK, et al. High prevalence of coeliac disease in Danish children with type I diabetes mellitus. Acta Paediatr 2001;90:1238-43. doi:10.1111/j.1651-2227.2001. tb01568.x

16 Cosnes J, Cellier C, Viola S, et al, Groupe D’Etude et de Recherche Sur la Maladie Coeliaque. Incidence of autoimmune diseases in celiac disease: protective effect of the gluten-free diet. Clin Gastroenterol Hepatol 2008;6:753-8. doi:10.1016/j.cgh.2007.12.022

17 Sildorf SM, Fredheim S, Svensson J, Buschard K. Remission withou insulin therapy on gluten-free diet in a 6-year old boy with type 1 diabetes mellitus. BMJ Case Rep 2012;2012:bcr0220125878. doi:10.1136/bcr.02.2012.5878

18 Svensson J, Sildorf SM, Pipper CB, et al. Potential beneficial effects of a gluten-free diet in newly diagnosed children with type 1 diabetes: a pilot study. Springerplus 2016;5:994. doi:10.1186/ s40064-016-2641-3

19 Ziegler AG, Bonifacio E, BABYDIAB-BABYDIET Study Group. Age-related islet autoantibody incidence in offspring of patients with type 1 diabetes. Diabetologia 2012;55:1937-43. doi:10.1007/s00125-012-2472-x

20 Parikka V, Näntö-Salonen K, Saarinen M, et al. Early seroconversion and rapidly increasing autoantibody concentrations predict prepubertal manifestation of type 1 diabetes in children at genetic risk. Diabetologia 2012;55:1926-36. doi:10.1007/s00125-012-2523-3

21 Ziegler AG, Rewers M, Simell O, et al. Seroconversion to multiple islet autoantibodies and risk of progression to diabetes in children. JAMA 2013;309:2473-9. doi:10.1001/jama.2013.6285

22 Culina S, Gupta N, Boisgard R, et al. Materno-fetal transfer of preproinsulin through the neonatal Fc receptor prevents autoimmune diabetes. Diabetes 2015;64:3532-42. doi:10.2337/db15-0024 
23 Lamb MM, Myers MA, Barriga K, Zimmet PZ, Rewers M, Norris JM. Maternal diet during pregnancy and islet autoimmunity in offspring. Pediatr Diabetes 2008;9:135-41. doi:10.1111/j.13995448.2007.00311.x

24 Virtanen SM, Uusitalo L, Kenward MG, et al. Maternal food consumption during pregnancy and risk of advanced $\beta$-cell autoimmunity in the offspring. Pediatr Diabetes 2011;12:95-9. doi:10.1111/j.1399-5448.2010.00668.x

25 Olsen J, Melbye M, Olsen SF, et al. The Danish national birth cohort--its background, structure and aim. Scand J Public Health 2001;29:300-7. doi:10.1177/14034948010290040201

26 Nohr EA, Frydenberg M, Henriksen TB, Olsen Does low participation in cohort studies induce bias? Epidemiology 2006;17:413-8. doi:10.1097/01. ede.0000220549.14177.60

27 Svensson J, Marinelli K, Eising S, Danish Childhood Diabetes Register, National Discharge Register. [Comparison of registration of data from the Danish Childhood Diabetes Register and The National Discharge Register]. Ugeskr Laeger 2007;169:122-5.

28 Patterson CC, Gyürüs E, Rosenbauer J, et al. Trends in childhood type 1 diabetes incidence in Europe during 19892008: evidence of non-uniformity over time in rates of increase. Diabetologia 2012;55:2142-7. doi:10.1007/s00125-012-2571-8

29 Olsen SF, Mikkelsen TB, Knudsen VK, et al. Data collected on maternal dietary exposures in the Danish National Birth Cohort. Paediatr Perinat Epidemiol 2007;21:76-86. doi:10.1111/j.1365 3016.2007.00777.x

30 Andersen LT, Jensen $H$, Haraldsdottir J. Typiske vægte for madvarer. Scand I Nutr 1996:40:S129-52.

31 Danish Food Composition Databank (2007). https://frida.fooddata. $\mathrm{dk} /$.

32 Ellis HI, Freedman AR, Ciclitira PJ. Detection and estimation of the barley prolamin content of beer and malt to assess their suitability for patients with coeliac disease. Clin Chim Acta 1990;189:123-30. doi:10.1016/0009-8981(90)90082-4

33 Gellrich CSP, Weiser H. Biochemical characterization and quantification of the storage protein (secalin) types in rye flour. Cereal Chem 2003;80:102-9. doi:10.1094/CCHEM.2003.80.1.102.

34 Hoppe C. Trolle E, Gondolf UH, Husby S. Gluten intake in 6-36-month-old Danish infants and children based on a national survey. J Nutr Sci 2013;2:e7. doi:10.1017/jns.2013.1

35 Hoppe C, Gøbel R, Kristensen M, et al. Intake and sources of gluten in 20- to 75-year-old Danish adults: a national dietary survey. Eur J Nutr 2017;56:107-17. doi:10.1007/s00394-015-1062-3

36 Lebwohl B, Cao Y, Zong G, et al. Long term gluten consumption in adults without celiac disease and risk of coronary heart disease: prospective cohort study. BMJ 2017;357:j1892 doi:10.1136/bmj.j1892

37 Willett W. Nutritional epidemiology. Oxford University Press, 1990: 273-307.

38 Rainone V, Schneider L, Saulle I, et al. Upregulation of inflammasome activity and increased gut permeability are associated with obesity in children and adolescents. Int J Obes (Lond) 2016;40:1026-33. doi:10.1038/ijo.2016.26

39 Claesson MJ, Jeffery IB, Conde S, et al. Gut microbiota composition correlates with diet and health in the elderly. Nature 2012;488:178 84. doi:10.1038/nature11319

40 Ding S, Lund PK. Role of intestinal inflammation as an early event in obesity and insulin resistance[doi]. Curr Opin Clin Nutr Metab Care 2011;14:328-33. doi:10.1097/MCO.0b013e3283478727

41 Lindehammer SR, Fex M, Maziarz M, Hanson I, Maršál K, Lernmark A, Diabetes Prediction in Skåne (DiPiS) Study Group. Early-pregnancy cytokines in mothers to children developing multiple, persistent islet autoantibodies, type 1 diabetes, or both before 7 years of age. Am I Reprod Immunol 2011;66:495-503. doi:10.1111/j.1600-0897.2011.01057.x
42 Damms-Machado A, Louis S, Schnitzer A, et al. Gut permeability is related to body weight, fatty liver disease, and insulin resistance in obese individuals undergoing weight reduction. Am J Clin Nutr 2017;105:127-35. doi:10.3945/ajcn.116.131110

43 Bruun SW, Josefsen K, Tanassi JT, et al. Large gliadin peptides detected in the pancreas of NOD and healthy mice following oral administration. J Diabetes Res 2016;2016:2424306 doi:10.1155/2016/2424306

44 Hussen HI, Persson M, Moradi T. Maternal overweight and obesity are associated with increased risk of type 1 diabetes in offspring of parents without diabetes regardless of ethnicity. Diabetologia 2015;58:1464-73. doi:10.1007/s00125-015-3580-1

45 Whitaker RC. Predicting preschooler obesity at birth: the role of maternal obesity in early pregnancy. Pediatrics 2004;114:e29-36. doi:10.1542/peds.114.1.e29

46 Holder T, Giannini C, Santoro N, et al. A low disposition index in adolescent offspring of mothers with gestational diabetes: a risk marker for the development of impaired glucose tolerance in youth. Diabetologia 2014;57:2413-20. doi:10.1007/s00125-014-3345-2

47 Erkkola M, Karppinen M, Javanainen J, Räsänen L, Knip M, Virtanen SM. Validity and reproducibility of a food frequency questionnaire for pregnant Finnish women. Am J Epidemiol 2001;154:466-76. doi:10.1093/aje/154.5.466

48 Robinson S, Godfrey K, Osmond C, Cox V, Barker D. Evaluation of a food frequency questionnaire used to assess nutrient intakes in pregnant women. Eur J Clin Nutr 1996;50:302-8.

49 Willett W. Nutritional epidemiology. 3rd ed. Oxford University Press, 2012. doi:10.1093/acprof:oso/9780199754038.001.0001

50 Beyerlein A, Chmiel R, Hummel S, Winkler C, Bonifacio E, Ziegler AG. Timing of gluten introduction and islet autoimmunity in young children: updated results from the BABYDIET study. Diabetes Care 2014;37:e194-5. doi:10.2337/dc14-1208

51 Chmiel R, Beyerlein A, Knopff A, Hummel S, Ziegler AG, Winkler C. Early infant feeding and risk of developing islet autoimmunity and type 1 diabetes. Acta Diabetol 2015;52:621-4. doi:10.1007/ s00592-014-0628-5

52 Uusitalo U, Lee HS, Andrén Aronsson C, et al, TEDDY Study Group. Early Infant Diet and Islet Autoimmunity in the TEDDY Study. Diabetes Care 2018;41:522-30. doi:10.2337/dc17-1983

53 Cardwell CR, Stene LC, Joner G, et al Caesarean section is associated with an increased risk of childhood-onset type 1 diabetes mellitus: a meta-analysis of observational studies. Diabetologia 2008;51:726-35. doi:10.1007/s00125-008-0941-z

54 Romano-Keeler J, Weitkamp JH. Maternal influences on fetal microbial colonization and immune development. Pediatr Res 2015;77:189-95. doi:10.1038/pr.2014.163

55 Thum C, Cookson AL, Otter DE, et al. Can nutritional modulation of maternal intestinal microbiota influence the development of the infant gastrointestinal tract? J Nutr 2012;142:1921-8. doi:10.3945/ jn.112.166231

56 Lund-Blix NA, Dydensborg Sander S, Størdal K, et al. Infant feeding and risk of type 1 diabetes in two large Scandinavian birth cohorts. Diabetes Care 2017:40:920-7. doi:10.2337/dc17-0016

57 Zipitis CS, Akobeng AK. Vitamin D supplementation in early childhood and risk of type 1 diabetes: a systematic review and meta-analysis. Arch Dis Child 2008;93:512-7. doi:10.1136/ adc. 2007.128579

58 Uusitalo U, Lee HS, Aronsson CA, et al, Environmental Determinants of the Diabetes in the Young (TEDDY) study group. Gluten consumption during late pregnancy and risk of celiac disease in the offspring: the TEDDY birth cohort. Am J Clin Nutr 2015;102:1216-21 doi:10.3945/ajcn.115.119370

\section{Web appendix: Supplementary tables}

